\title{
Roles of Src family kinase signaling during fertilization and the first cell cycle in the marine protostome worm Cerebratulus
}

\author{
STEPHEN A. STRICKER*,1, DAVID J. CARROLL² and WAI L. TSUI ${ }^{1}$ \\ ${ }^{1}$ Department of Biology, University of New Mexico, Albuquerque, NM, USA and \\ ${ }^{2}$ Department of Biological Sciences, Florida Institute of Technology, Melbourne, FL, USA
}

\begin{abstract}
For eggs to generate a calcium response during fertilization, the sperm of many deuterostome animals must first activate a group of egg kinases, called Src family kinases (SFKs). However, whether SFK activation is also required for fertilization-induced calcium signals in eggs of protostomes remains unknown. Thus, in this study, unfertilized oocytes of the marine protostome worm Cerebratulus were treated with either PP2 to inhibit SFKs or with U73122 to block phospholipase C activity downstream of SFK. Compared with control fertilizations, the inhibitors significantly reduced post-insemination levels of polar body formation and cleavage, but apparently did so via different mechanisms, based on the variable effects of these drugs on sperm incorporations and pronuclear differentiation. Moreover, confocal calcium imaging revealed that repetitive calcium waves (=oscillations) were blocked by U73122, but not by PP2, even though immunoblots indicated SFK activity was inhibited by PP2. Such findings fail to support the view that SFKs are required for initiating fertilization-induced calcium oscillations in Cerebratulus, and alternative mechanisms for the observed inhibition of polar body formation and cleavage in drug-treated specimens are discussed.
\end{abstract}

KEY WORDS: egg activation, nemertean, PLC, PP2, U73122

\section{Introduction}

During fertilization, the egg cytoplasm undergoes an elevation in calcium ions $\left(\mathrm{Ca}^{2+}\right)$ that is primarily regulated by the secondary messenger inositol 1,4,5 trisphosphate $\left(\mathrm{IP}_{3}\right)$ in both deuterostomes (e.g. chordates and echinoderms) and protostomes (e.g. arthropods, molluscs, and various worms) (Stricker 1999; Whitaker 2006). To initiate $\mathrm{IP}_{3}$-mediated $\mathrm{Ca}^{2+}$ release, sperm can introduce into the egg a soluble factor that in mammals and a few other vertebrates represents a sperm-specific phospholipase C (PLC), termed PLC $\zeta$ (Saunders et al. 2002; Coward et al. 2005; Ito et al. 2008). PLC $\zeta$, along with resident PLCs in the egg, generates $I_{3}$ by phospholipid hydrolysis, and after binding to its receptors on the egg's endoplasmic reticulum $(E R), I_{3}$ releases stored $\mathrm{Ca}^{2+}$ to generate a single $\mathrm{Ca}^{2+}$ elevation or multiple $\mathrm{Ca}^{2+}$ oscillations (Swann and Yu 2008).

Alternatively, or in addition, sperm may stimulate egg tyrosine kinases, called Src family kinases (SFKs), that activate PLC $\gamma$ to yield IP ${ }_{3}$ (Runft et al.2002). Signaling through SFKs is required for $\mathrm{Ca}^{2+}$ release during fertilization in such deuterostomes as echinoderms, ascidians, and fish (Kinsey and Shen 2000; Runft and
Jaffe 2000; Kinsey et al. 2003). Similarly, SFKs mediate the fertilization-induced $\mathrm{Ca}^{2+}$ response of the frog Xenopus (Sato et al. 2000, 2006), albeit by different mechanisms than in other deuterostomes (Runft et al. 2002). Conversely, although mammalian eggs express SFKs, such kinases are apparently not necessary for initiating $\mathrm{Ca}^{2+}$ oscillations (Kurokawa et al. 2004; Mehlmann and Jaffe 2005; Meng et al. 2006; Tomashov-Matar et al. 2007).

In protostomes, eggs of the annelid worm Chaetopterus contain a PLC $\gamma$ (Yin and Eckberg 2009), and not only does the PLC blocker U73122 prevent sperm factor-mediated $\mathrm{Ca}^{2+}$ release in Chaetopterus (Howell et al. 2003), but U73122 and tyrosine kinase blockers also inhibit egg activation and cleavage (Howell et al. 2003; Yin and Eckberg 2009). Similarly, $\mathrm{Ca}^{2+}$ is elevated during fertilization and egg activation in the protostomes Caenorhabditis and Drosophila (Samuel et al. 2001; Horner et al. 2008), and oocytes of marine protostome worms in the phylum

Abbreviations used in this paper: ER, endoplasmic reticulum; MPF, maturationpromoting factor; pb, polar body; SFK, Src family kinase; SW, seawater.

\footnotetext{
*Address correspondence to: Stephen A. Stricker. Department of Biology, 1 University of New Mexico, MSC03 2020, Albuquerque, NM, 87131-0001, USA. e-mail: sstr@unm.edu
} 
Nemertea generate $\mathrm{Ca}^{2+}$ oscillations upon fertilization via mechanisms apparently involving sperm factor- and $\mathrm{IP}_{3}$-mediated signaling (Stricker 1996, 1997). However, whether SFKs are required for fertilization-induced $\mathrm{Ca}^{2+}$ release in protostomes remains unknown. Thus, in this study, oocytes of the nemertean Cerebratulus sp. were fertilized after treatments with PP2 or U73122 to inactivate SFKs or PLC, respectively, and such fertilizations were analyzed by Hoechst labeling, confocal calcium imaging, and immunoblots to assess the roles of SFK signaling. ditions of $\mathrm{U} 73122$, and unlike the $96+/-10 \%(\mathrm{~N}=3)$ rate of polar body formation in controls without U73122 addition, essentially no polar bodies were formed when U73122 was added 5-15 min after sperm addition (Fig. 1E) i.e., at times that occur after normal $\mathrm{Ca}^{2+}$ response onset (Stricker and Smythe 2003). Furthermore, fertilizations in $5 \mu \mathrm{M}$ U73122 or after $10 \mu \mathrm{M}$ U73122 washouts yielded incomplete sperm incorporations (Fig. $1 \mathrm{~F}, \mathrm{G}$ ), and oocytes incubated in U73122+DTT were less wrinkled than in U73122 alone (Fig. $1 \mathrm{H}, \mathrm{I}$ ), collectively indicating that U73122 affected oocyte

\section{Results}

\section{Antagonists of SFKs or PLC inhib- ited post-fertilization polar body for- mation and cleavage}

PP2 and U73122 significantly reduced $(P<0.05)$ the number of polar body forming oocytes at 30 min postinsemination, compared to controls in seawater (SW) (Fig. 1A). By contrast, fertilizations in either inactive PP2 (=PP3) or in U73122 pre-treated with $10 \mathrm{mM}$ dithiothreitol (DTT) to reduce U73122's activity (Lee and Shen, 1998) allowed polar body formation (Fig. 1A). Similarly, SW controls generated normal 2-cell embryos, whereas U73122 eliminated cleavage, and PP2 yielded mostly uncleaved eggs along with some overtly polyspermic cleavages (Fig. 1 $\mathrm{B}, \mathrm{C})$. PP3 or U73122+DTT also decreased normal cleavages (Fig. 1B), but significantly more $(P<0.05) 2$-cell embryos occurred in PP3 or U73122+DTT than in PP2 or U73122 alone.

\section{U73122 inhibited sperm incorpora- tion, whereas PP2 increased polyspermy}

Based on Hoechst staining, sperm incorporations were significantly decreased $(\mathrm{P}<0.05)$ by $10 \mu \mathrm{M} U 71322$ (Fig. 1D). Although such reductions could have resulted from U71322 inhibiting sperm motility (Harayama et al. 2005), polar body formation and cleavage were still negligible $(1.3+/-2.3 \%, 0+/-0 \%, \mathrm{~N}=3)$ in $5 \mu \mathrm{M}$ U73122 treatments that had increased sperm incorporations (Fig. 1D). In addition, when oocytes were pre-incubated in $10 \mu \mathrm{M}$ U73122 and washed with drug-free SW directly before insemination, sperm incorporations were elevated over those in $5 \mu \mathrm{M} U 73122$ (Fig. 1D), but polar body formation and cleavage were still blocked $(0+/-0 \%$, $0+/-0 \%, N=3)$. Similarly, oocytes were fertilized in SW before subsequent ad-
A
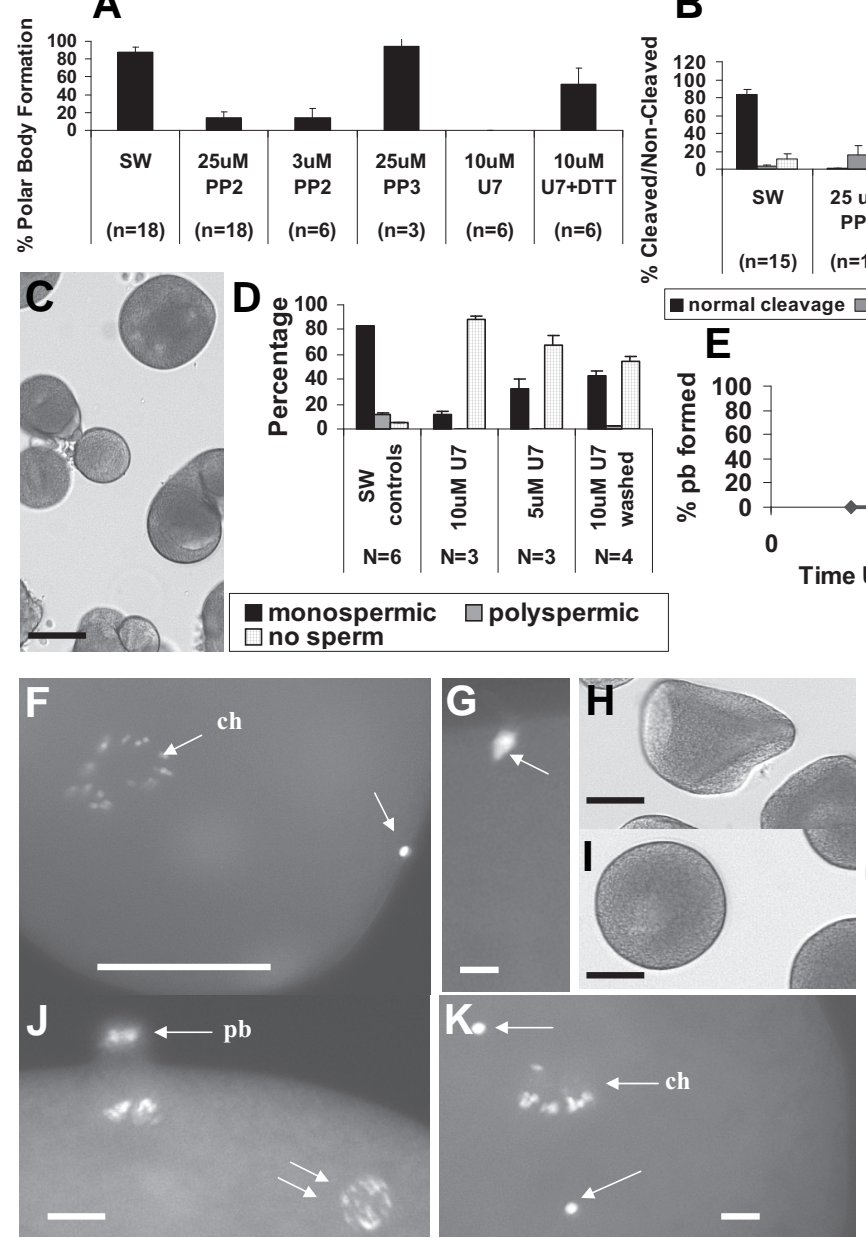

B
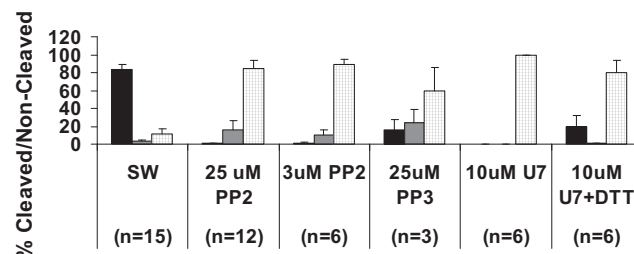

normal cleavage $\square$ polyspermic cleavage $\square$ no cleavage
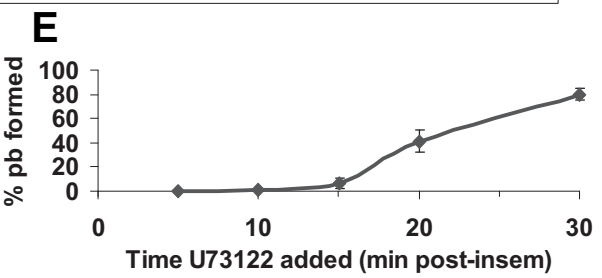

$\mathbf{L}$

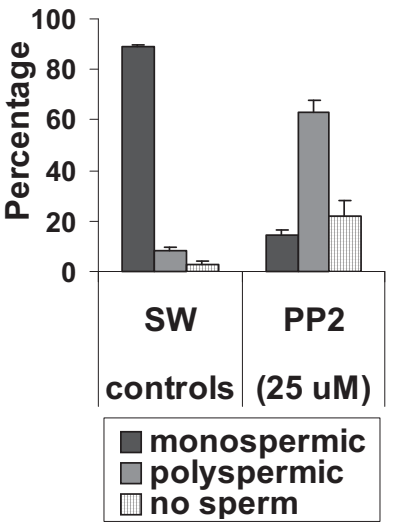

Fig. 1. Effects of inhibitors of SFKs (PP2) and PLC (U73122; “U7") on polar body (pb) formation, cleavage, sperm incorporation and pronuclear development. Polar body formation at $30 \mathrm{~min}$ (A) and cleavage at $2.5 \mathrm{~h}$ (B) are blocked by PP2 and U73122, whereas less active drug forms (PP3) and (U7+DTT) yield levels more like SW controls; note: polar body counts were subjected to a scaling factor (see Methods and Materials). (C) Abnormal cleavage in PP2; n=number of oocyte batches counted. (D) Compared to controls, both $5 \mu \mathrm{M}$ U73122 and $10 \mu \mathrm{M}$ U73122 either without or with a washout in SW before sperm addition (10 $\mu \mathrm{M} U 7$ washed) significantly $(P<0.05)$ reduce sperm incorporations. (E) Adding $10 \mu \mathrm{M}$ U73122 at 5,10,15, or 20 min post-insemination in SW significantly $(P<0.05 ; N=3)$ reduces polar body formation at $45 \mathrm{~min}$, compared to controls $(96+/-10 \% ; N=3)$, suggesting $U 73122$ affects eggs, rather than simply the ability of sperm to fertilize. $(\mathbf{F}, \mathbf{G})$ Hoechst-labeled oocytes in 10 $\mu M \mathrm{U} 73122$, showing incorporated sperm (arrows) that failed to migrate toward egg chromosomes (Ch). (H,I) U73122-treated oocytes before (E) and after (F) $10 \mathrm{mM}$ DTT addition to reduce U73122 activity, showing less wrinkling after U73122 deactivation. (J-L) Compared to controls, PP2 treatments increase polyspermy ( $P<0.05 ; \mathrm{N}=3$ ) (L). (J,K) Hoechst-labeled control (J) vs. PP2-treated (K) oocyte at 60 min post-insemination, showing normal decondensed male pronucleus (double arrows) after polar body (pb) formation vs. still condensed male pronuclei (arrows) in polyspermic PP2-treated oocyte; ch, chromosomes; scale bars, $50 \mu \mathrm{m}(\mathrm{C}, F, H, I)$ and $10 \mu \mathrm{m}(G, J, K)$. 
function.

Conversely, PP2 triggered significantly higher rates of polyspermy $(P<0.05)$ (Fig. $1 \mathrm{~J}-\mathrm{L})$, with each polyspermic PP2treated oocyte averaging 3.6+/-1.5 incorporated sperm $(\mathrm{N}=50)$. Furthermore, male pronuclei in PP2 treatments typically reached the oocyte interior but failed to decondense after controls had done so (Fig. $1 \mathrm{~J}, \mathrm{~K}$ ).

\section{Fertilization-induced $\mathrm{Ca}^{2+}$ oscillations were inhibited by U73122 but not by PP2}

Control oocytes fertilized in SW underwent a peripheral "cortical flash" (Stricker 1996) of apparent $\mathrm{Ca}^{2+}$ influx during sperm-egg binding (Fig. 2A). Such flashes began 2-4 min post-insemination and were sometimes generated after an initial artifactual rise caused by changes in oocyte shape or position during sperm addition. Subsequently, each flash was followed by $\sim 6-12 \mathrm{Ca}^{2+}$ waves that spread across the ooplasm (Fig. 2 A,B,J) and typically ceased by $\sim 20-25$ min post-insemination (Table I).
For U73122 fertilizations (Fig. 2 C-E), oocytes were incubated 30-60 min in 5 $\mu \mathrm{M} U 73122$ before multiple sperm additions that ensured $>50-100$ sperm surrounded each oocyte. In spite of sperm availability, significantly fewer U73122-treated oocytes displayed $\mathrm{Ca}^{2+}$ oscillations $(\mathrm{P}<0.05)$ (Fig. 1B). Among non-oscillating specimens, 9/12 exhibited cortical flash-like elevations and/ or non-propagating cortical "hot spots" (Glahn et al. 1999) (Fig. 2 $\mathrm{C}, \mathrm{I})$. Similarly, when oocytes were fertilized in SW and allowed to elevate $\mathrm{Ca}^{2+}$ before U73122 addition, 5/12 completed normal oscillations, whereas in the other $7, \mathrm{Ca}^{2+}$ waves were prematurely terminated $(\mathrm{N}=5)$ or markedly dampened in amplitude and frequency $(\mathrm{N}=2)$ (Fig. $2 \mathrm{D}, \mathrm{E})$.

In contrast, 15/17 PP2-treated oocytes continued to generate $\mathrm{Ca}^{2+}$ oscillations that traversed the ooplasm (Table 1; Fig. $2 \mathrm{~F}$ $\mathrm{H}, \mathrm{K}$ ). Of these oscillations, 4 terminated within $\sim 20-25 \mathrm{~min}$ (Table I), whereas 11 continued beyond $30 \mathrm{~min}$. In addition, a prominent cortical flash was typically lacking in PP2 treatments, as most $\mathrm{Ca}^{2+}$ responses began with repetitive waves (Fig. 2F).
Fig. 2. $\mathrm{Ca}^{2+}$ dynamics. (A). Ratioed confocal data from SW control, showing sperm addition (arrow), cortical flash (cf), and repetitive $\mathrm{Ca}^{2+}$ waves (=oscillations). (B) Percentages of: i) normal $\mathrm{Ca}^{2+}$ oscillations, ii) abnormal $\mathrm{Ca}^{2+}$ oscillations that did not terminate by 30 min post-insemination, or iii) no $\mathrm{Ca}^{2+}$ oscillations. (C) Fertilization in $5 \mu \mathrm{M}$ U73122, showing sperm additions (arrows), cortical flash (cf), and cortical "hot spots" (double arrowheads) without $\mathrm{Ca}^{2+}$ oscillation production. (D,E) Fertilizations with sperm added (arrow) in SW prior to $10 \mu \mathrm{M} U 73122$ addition; note rapid termination of $\mathrm{Ca}^{2+}$ oscillations (D) or marked dampening in amplitude and frequency (E). (F) Fertilization-induced $\mathrm{Ca}^{2+}$ oscillations in PP2-treated oocyte after sperm addition (arrow) $(\mathbf{G}, \mathbf{H}) \mathrm{Ca}^{2+}$ waves from PP2treated specimen in $K$, confirming global nature of $\mathrm{Ca}^{2+}$ waves, albeit with higher rises in periphery vs. center of oocyte. (I) Non-ratioed images of oocyte cortex during fertilization in $5 \mu \mathrm{M}$ U73122; images were not divided by the initial image of time-lapse run to show a subtle "hot spot" of localized $\mathrm{Ca}^{2+}$ elevation (arrow). (J) Images divided by the initial image of the time-lapse run, showing last $\mathrm{Ca}^{2+}$ waves (arrows) during control fertilization. (K) Repetitive $\mathrm{Ca}^{2+}$ waves (arrows) produced during fertilization in $25 \mu \mathrm{MPP} 2$ (arrows); images were left unratioed, since cell shape changes would cause distortions; scale bars, $50 \mu \mathrm{m}$.
A
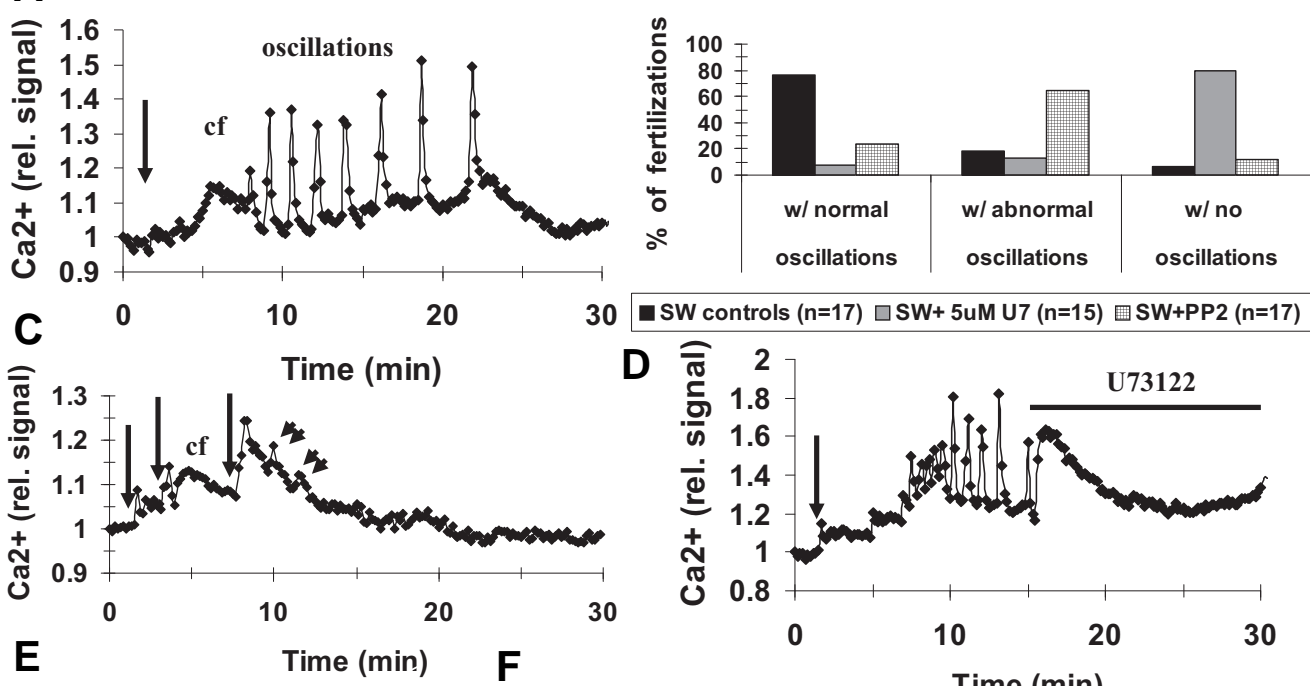

$\square$ SW controls $(n=17) \square S W+5 u M U 7(n=15) \square S W+P P 2(n=17)$
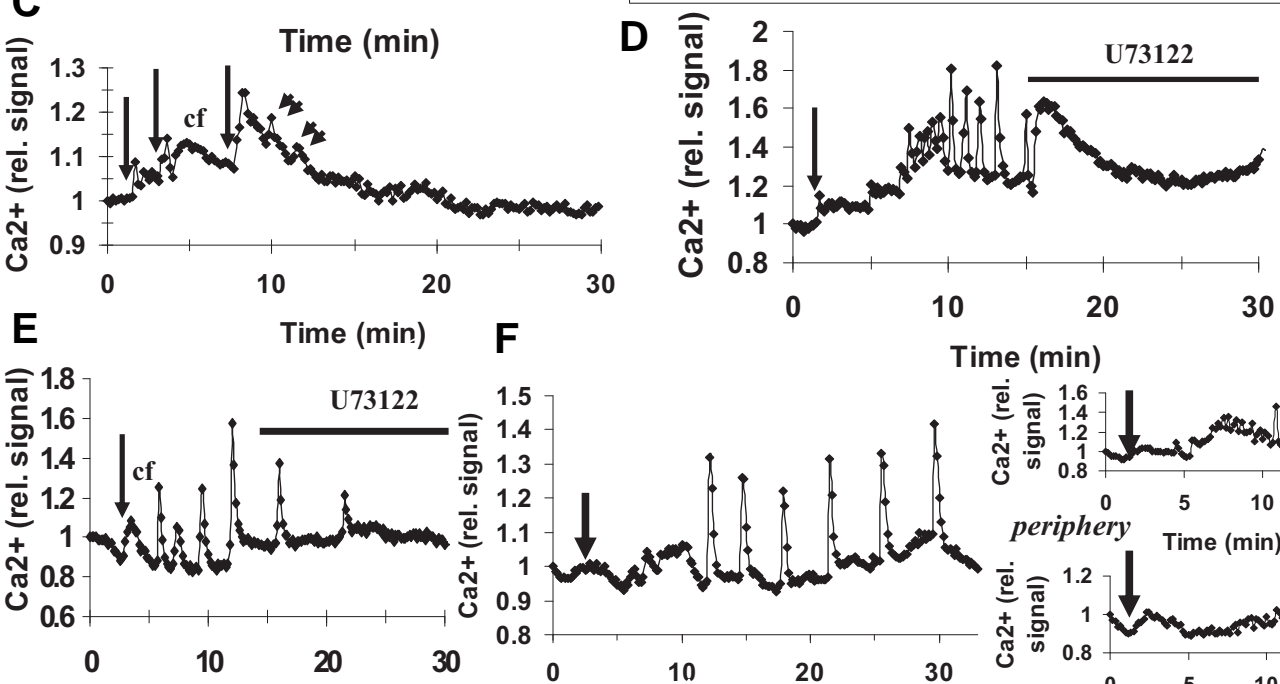

Time (min)
30

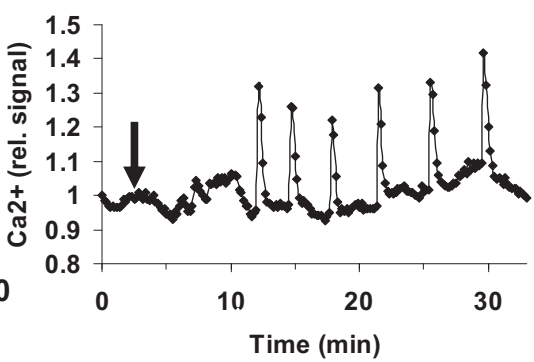

Time (min)

G
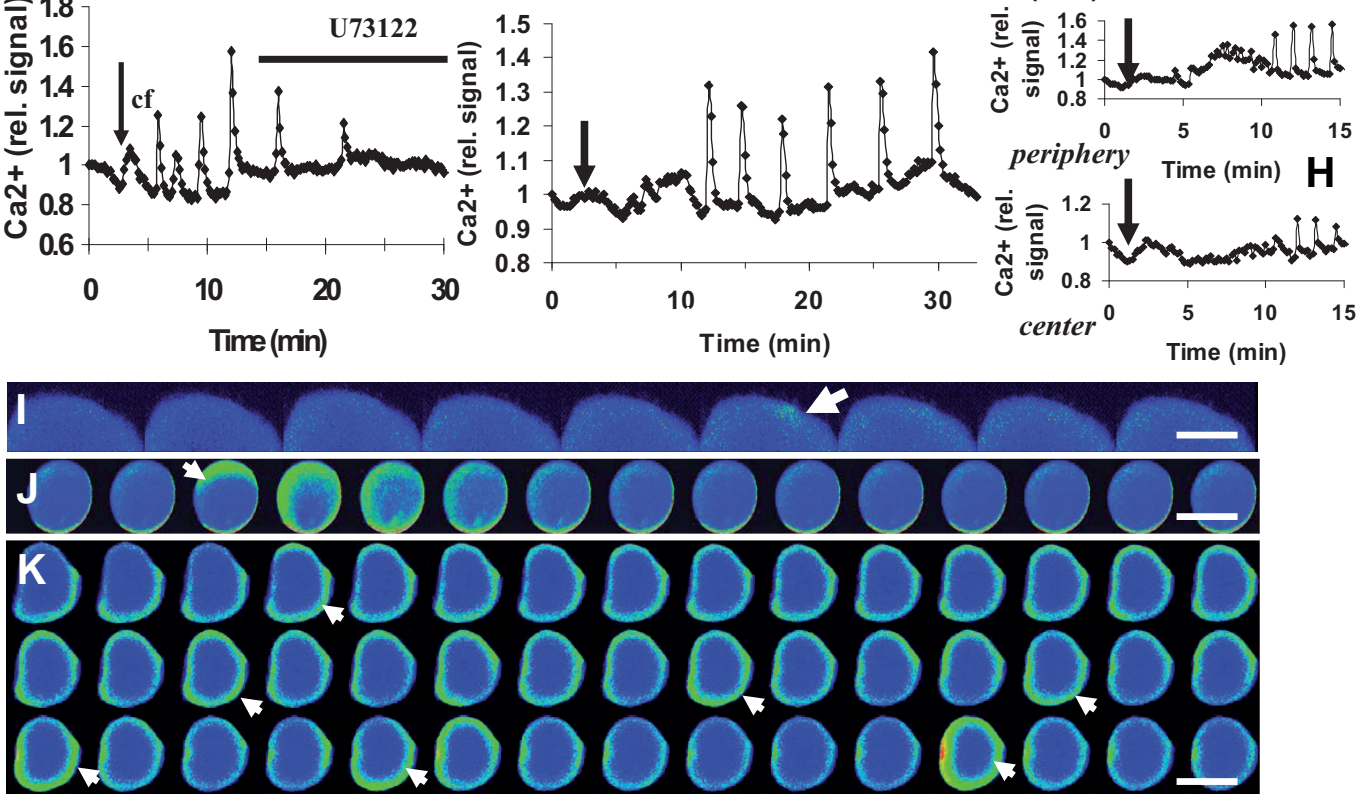
TABLE 1

FERTILIZATION-INDUCED Ca ${ }^{2+}$ OSCILLATIONS IN PP2-TREATED OOCYTES

\begin{tabular}{|c|c|c|c|c|c|}
\hline & $\begin{array}{l}\text { Percentage of Fertilizations } \\
\text { Generating } \mathrm{Ca}^{2+} \text { Oscillations }\end{array}$ & $\begin{array}{l}\text { Average Number of } \mathrm{Ca}^{2+} \text { Spikes } \\
\text { Produced by Oscillating Oocytes } \\
\text { during } 33 \mathrm{~min} \text { of Imaging }\end{array}$ & $\begin{array}{l}\text { Average Increase in Peak } \\
\text { Amplitude of } \mathrm{Ca}^{2+} \text { Spikes } \\
\text { over Baseline Levels* }\end{array}$ & $\begin{array}{l}\text { Average Time of } \mathrm{Ca}^{2+} \\
\text { Oscillation Onset Relative } \\
\text { to Sperm Addition* }\end{array}$ & $\begin{array}{l}\text { Average Time of } \mathrm{Ca}^{2+} \\
\text { Oscillation Termination } \\
\text { Relative to Sperm Addition }\end{array}$ \\
\hline SW controls & $94 \%(16 / 17)$ & $8.9+/-2.2(\mathrm{~N}=16)$ & $\begin{array}{l}37.8+/-13.3 \% \\
(\mathrm{~N}=16)\end{array}$ & $\begin{array}{l}6.2+/-1.2 \min \\
(\mathrm{N}=16)\end{array}$ & $\begin{array}{l}20.7+/-1.8 \mathrm{~min} \\
(\mathrm{~N}=16)\end{array}$ \\
\hline PP2-treated oocytes & $88 \%(15 / 17)$ & $10.2+/-3.8(\mathrm{~N}=15)$ & $\begin{array}{l}64.5+/-25.3 \% \\
(\mathrm{~N}=15)\end{array}$ & $\begin{array}{l}7.6+/-1.4 \min \\
(\mathrm{N}=15)\end{array}$ & $>30 \min (\mathrm{N}=11)^{\star \star}$ \\
\hline
\end{tabular}

*Does not include pre-oscillation "cortical flash"

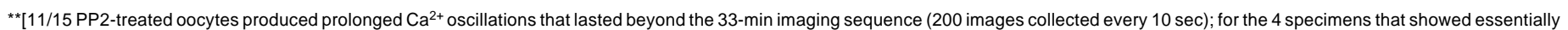
normal terminations, the oscillations ended at $24+/-2.8 \mathrm{~min}$ after sperm addition].

\section{Immunoblotting analyses verified that PP2 inhibited SFK activity and cell cycle progression}

Unfertilized oocytes probed with a phospho-specific antibody against active SFKs displayed a signal in the 52-62 kD range of known SFKs (Thomas and Brugge 1997) that was reduced by PP2, but not PP3 (Fig. 3 A,B). In well-resolved blots, the 55-60 kD band comprised a doublet, and in 2/12 cases, a band of unknown significance occurred at $\sim 52 \mathrm{kD}$ (Fig. 3C, arrow), collectively suggesting oocytes possess multiple SFKs or an SFK with alternative electrophoretic mobilities. Following fertilization in SW or SW+PP3, the SFK signal remained fairly steady (Fig. $3 \mathrm{C}-\mathrm{E}$ ), although 4/12 controls displayed a moderate increase (Fig. 3F). Conversely, PP2 significantly $(\mathrm{P}<0.05)$ reduced this signal (Fig. 3 A-G), as noted for somatic cells (Feistritzer et al. 2005).

In correlative assays of cell cycle regulators, both MAPK (mitogen-activated protein kinase) and maturation-promoting factor (MPF) activities decreased in fertilized controls (Fig. $3 \mathrm{C}, \mathrm{E}$ ), as noted previously (Stricker 2009b). Alternatively, MAPK levels in
PP2 averaged $33+/-34 \%(\mathrm{~N}=7)$ of control values at 30 min postinsemination, but MPF remained relatively active in 6/7 PP2 treatments (Fig. 3D), coinciding with the PP2-induced block in polar body formation (Fig. 1A).

\section{Discussion}

Although proteins in protostome eggs undergo tyrosine phosphorylation after fertilization (e.g. Shibuya etal. 1992; Hinton etal. 2003), their depicted MWs are not SFK-like. Thus, experiments described here provide the first analysis of how SFK signaling affects fertilization-induced $\mathrm{Ca}^{2+}$ signals in a protostome. It should be noted, however, that drugs used in this study can have ectopic effects on unintended targets (Bain et al. 2003). Nevertheless, until genomic data become available and baseline information regarding signaling pathways in these worms is assembled, such inhibitors provide an initial means of analysis that albeit requires cautious interpretation (Fig. 4).

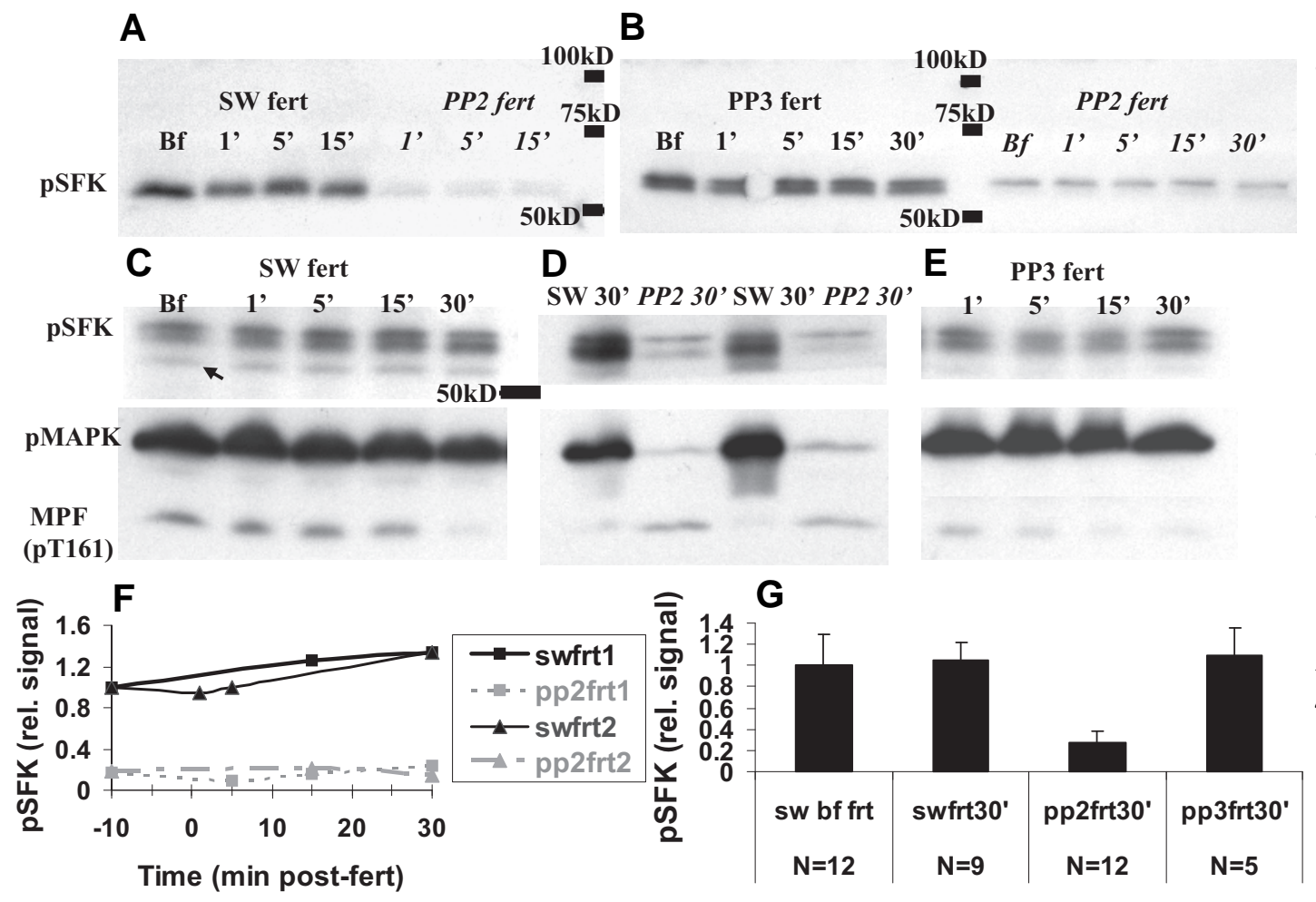

Fig. 3. SFK, MAPK, and MPF activities during the first 30 min post-fertilization. (A-E) Control oocytes before insemination ("Bf") display putative SFK bands at 55-60 kD that are reduced by $25 \mu \mathrm{M} P P 2$ but not by $25 \mu \mathrm{M}$ PP3; arrow in $\mathrm{C}$ marks $\sim 52-k D$ band of unknown significance observed in 2/12 blots. Treatments with $P P 2$ also reduce ERK 1/2 MAPK activity ("pMAPK") at 42 kD MW and prevent post-fertilization MPF deactivation as indicated by high phospho-Cdc2T161 signal ("pT161") at $\sim 32$ kD. (F) Two PP2 fertilizations ("pp2frt1 or 2") vs. control fertilizations in seawater alone ("swfrt1 or 2"). (G) At 30 min post-fertilization, 25 $\mu M P P 2$ causes statistically lower SFK activity at 55-60 kD ("pSFK") $(P<0.05)$ ("pp2frt30'") than in controls before fertilization ("swbffrt") or in control zygotes ("swfrt30'") or PP3-treated oocytes ("pp3frt30'") at $30 \mathrm{~min}$. 


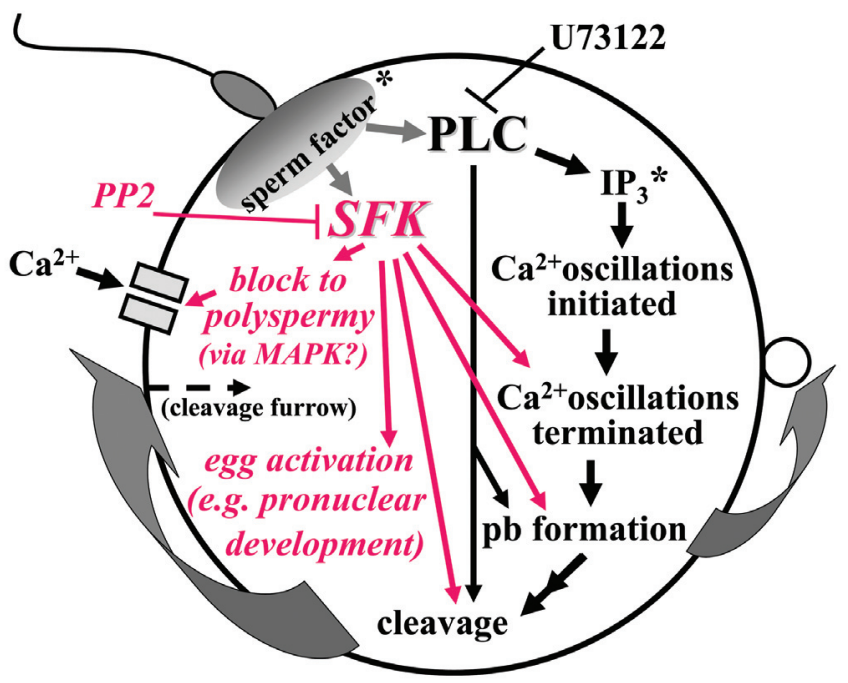

Fig. 4. Summary of results and their possible interpretations. Asterisks indicate parts based on previously published data (Stricker 1996, 1997). Judging from experiments reported here, fertilization-induced $\mathrm{Ca}^{2+}$ oscillations in Cerebratulus sp. depend on phospholipase C (PLC), but not Src family kinase (SFK), activity. However, active SFK(s) may modulate $\mathrm{Ca}^{2+}$ oscillation patterns (e.g. termination timing). Moreover, SFK and/or PLC activity might affect polyspermy prevention, pronuclear development, polar body (pb) formation, and cleavage. $I P_{3}=$ inositol 1,4,5 trisphosphate; MAPK=ERK 1/2 mitogen-activated.protein kinase.

\section{PLC and SFK inhibitors block polar body formation and cleavage with differing effects on sperm incorporation and pronuclei}

U73122 treatments reduce the number of sperm-containing oocytes, as noted for mouse or sea urchin eggs (Dupont et al. 1996; Lee and Shen 1998). However, U73122-treated Cerebratulus oocytes that possess sperm are mostly monospermic, which contrasts with U73122-induced polyspermy in sea urchins and Xenopus (Lee and Shen 1998; Sato et al. 2000). Alternatively, PP2 triggers polyspermy, as described for deuterostomes (Giusti et al. 1999; Kinsey and Shen 2000; Sato et al. 2000). PP2 also causes pronuclear abnormalities and cleavage defects, which is consistent with reports of deuterostome eggs treated with similar antagonists (Talmor-Cohen et al. 2004: $\mathrm{Ng}$ et al. 2005) or injected with SH2 (Src Homology 2) domains to inhibit SFKs (Meng et al. 2006; McGinnis et al. 2009).

\section{As opposed to PP2, U73122 can block $\mathrm{Ca}^{2+}$ oscillations with- out increasing polyspermy}

The absence of oscillations in U73122 is not due to a lack of sperm-egg interactions, since non-oscillating specimens commonly undergo cortical flash-like increases or "hot spots" (Glahn et al. 1999). Similarly, $>50 \%$ of Cerebratulus oocytes treated with U73122 after fertilization discontinue their oscillations or display oscillation dampening. Although it remains to be determined if oscillations produced by some U73122-treated specimens are simply due to inadequate drug doses (Dupont et al. 1996; Deng et al. 1998; Lee and Shen 1998), the disruption of oscillations by U73122 suggests that $\mathrm{Ca}^{2+}$ signaling depends on PLC activity and that blocking this activity may account for the observed inhibition of cleavage and polar body formation. However, U73122- treated oocytes can produce $\mathrm{Ca}^{2+}$ oscillations without forming polar bodies or cleaving, indicating a possible additional requirement for PLC during cytokinesis ( $\mathrm{Ng}$ et al. 2005). Accordingly, 5$10 \mu \mathrm{M} U 73122$ doses may more effectively deactivate the putative PLC needed for cytokinesis than the PLC activity required for $\mathrm{Ca}^{2+}$ oscillations.

For Cerebratulus oocytes that incorporate sperm in U73122, few display polyspermy, as opposed to the $40-45 \%$ polyspermy rates of sea urchins or Xenopus (Lee and Shen 1998; Sato et al. 2000). Such monospermy may be related to the continued production of cortical flashes in U73122-treated specimens, since Cerebratulus lacteus oocytes prevent polyspermy via a prolonged oolemmal depolarization that requires a Ca${ }^{2+}$ rise (Kline et al. 1986). This rise in turn might result from $\mathrm{Ca}^{2+}$ influx during the cortical flash, given that a $\mathrm{Ca}^{2+}$ channel blocker inhibits cortical flashes and causes polyspermy (Stricker 1996). Accordingly, PP2 disrupts cortical flashes, deactivates MAPK, and causes polyspermy, suggesting that SFK, and/or downstream MAPK, activity may mediate normal cortical flash production and polyspermy prevention. In any case, as discussed below, such polyspermy is not due to a complete lack of a fertilization-induced $\mathrm{Ca}^{2+}$ response, as noted for some deuterostomes with disrupted SFK signaling (Kinsey and Shen 2000; Sato et al. 2000).

\section{PP2-treated oocytes produce prolonged $\mathrm{Ca}^{2+}$ oscillations that fail to promote cell cycle progression}

Nearly all Cerebratulus oocytes fertilized in PP2 still produce $\mathrm{Ca}^{2+}$ oscillations, even though immunoblots indicate PP2 deactivates SFK. Thus, in addition to $\mathrm{Ca}^{2+}$-independent mechanisms that have been proposed for SFKs' effects (Meng et al. 2006), PP2-treated oocytes undergoing $\mathrm{Ca}^{2+}$ oscillations may still fail to produce polar bodies or cleave, owing to the precise pattern of oscillations (Ducibella et al. 2006; Tomashov-Matar et al. 2007). For example, the persistent oscillations generated in PP2 may not allow the normal deactivation of MPF required for completing meiosis (Levasseur and McDougall 2000).

In any case, results reported here could signify either that fertilization-induced $\mathrm{Ca}^{2+}$ oscillations are generated independently of SFKs, or that SFK activity is actually required for such oscillations, but PP2 somehow allows an artifactual continuation of these $\mathrm{Ca}^{2+}$ signals. As potential confounding factors that cannot be precluded, $\mathrm{Ca}^{2+}$ oscillations might be initiated by residual SFK activity still present after PP2 incubation or by SFKs not reactive to the phospho-SFK antibody. Alternatively, PP2 may eliminate relevant SFK activity but cause additional defects that allow oscillation production. Moreover, a PP2-induced deactivation of SFK may by itself stimulate $\mathrm{Ca}^{2+}$ release, as suggested by one of the sea urchin SFKs that might actually inhibit, rather than trigger, $\mathrm{Ca}^{2+}$ release (Townley et al. 2009). To test these hypotheses, the type(s) of SFK(s) in Cerebratulus must be identified so that alternative means of inhibition such as $\mathrm{SH} 2$ domain injections can be utilized. In any case, findings presented here fail to support the view that SFK activity is required for generating fertilizationinduced $\mathrm{Ca}^{2+}$ oscillations in this protostome.

\section{Materials and Methods}

Oocytes of Cerebratulus sp. (Stricker 2009a) were treated with calcium-free seawater to minimize spontaneous germinal vesicle break- 
down (Stricker and Schatten 1989) before being matured in SW. Mature oocytes were incubated $\sim 1 \mathrm{hr}$ in SW with or without inhibitor before being fertilized with diluted sperm (Stricker 2009b) in the presence or absence of the inhibitor. Polar body assays at $30 \mathrm{~min}$ post-fertilization were adjusted for ephemeral or hidden polar bodies, by subjecting uncorrected counts of 50-100 oocytes per treatment to a scaling factor $(\sim 2 X)$ equaling the average of normally cleaving controls divided by the average of observed polar body-forming oocytes. Cleavage was assessed at $\sim 2.5 \mathrm{~h}$ post-fertilization, and sperm incorporations were tracked via Hoechst 33342 (Stricker 1996).

For immunoblots, oocytes were probed with phospho-specific antibodies (\#9101 phospho-ERK 1/2 MAPK, \#9114 phospho-T161 Cdc2 MPF, \#2101 phospho-Src family kinases from Cell Signaling, Beverly, MA, USA) (Stricker and Smythe 2003). Densitometry of backgroundsubtracted bands was carried out using MetaMorph software on at least three replicates from two or more females, and statistical assessments utilized a Mann-Whitney-U test.

To assay calcium dynamics, oocytes were microinjected with Calcium Green Dextran, 10,000 MW (Invitrogen; Carlsbad, CA, USA) and imaged with a confocal microscope (Stricker 1996). Fluorescence intensities were graphed for $\sim 15 \mu \mathrm{mX} 15 \mu \mathrm{m}$ regions-of-interest in the peripheral third of each oocyte, and such data were normalized relative to the starting fluorescence at the onset of imaging.

Stock solutions of inhibitors were mixed in DMSO, and working dilutions (3-25 $\mu \mathrm{M}$ for PP2; 5-10 $\mu \mathrm{M}$ for U73122) were toward the lower end of previously used doses that have ranged up to $100 \mu \mathrm{M}$ for PP2 (Kinsey

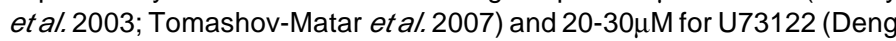
et al. 1998; Lee and Shen 1998).

\section{Acknowledgements}

We thank Friday Harbor Laboratories for use of their facilities, and apologize for articles that were not cited owing to limitations imposed on the reference section.

\section{References}

BAIN, J., MCLAUCHLAN, H., ELLIOTT, M., and COHEN, P. (2003). The specificities of protein kinase inhibitors: an update. Biochem J371: 199-204.

COWARD, K., PONTING, C.P., CHANG, H-Y., HIBBITT, O., SAVOLAINEN, P., JONES, K.T., and PARRINGTON, J. (2005). Phospholipase $C \zeta$, the trigger of egg activation in mammals, is present in a non-mammalian species. Reproduction 130: 157-163.

DENG, M-Q., HUANG, X-Y., TANG, T-S., and SUN, F-Z. (1998). Spontaneous and fertilization-induced $\mathrm{Ca}^{2+}$ oscillations in mouse immature germinal vesiclestage oocytes. Biol Reprod58: 807-813.

DUCIBELLA, T., SCHULTZ, R.M., and OZIL, J-P. (2006). Role of calcium signals in early development. Sem Cell Dev Bio. 17: 324-332.

DUPONT, G., MCGUINNESS, O.M., JOHNSON, M.H., BERRIDGE, M.J., and BORGESE, F. (1996). Phospholipase C in mouse oocytes: characterization of $\beta$ and $\gamma$ isoforms and their possible involvement in sperm-induced $\mathrm{Ca}^{2+}$ spiking. Biochem J316: 583-591.

FEISTRITZER, C., MOSHEIMER, B.A., TANCEVSKI, I., KANEIDER, N.C., STURN, D.H., PATSCH, J.R., and WIDERMANN, C.J. (2005). Src tyrosine kinasedependent migratory effects of antithrombin in leukocytes. Exp Cell Res 305: 214-220.

GIUSTI, A.F., CARROLL, D.J., ABASSI, Y.A., TERASAKI, M., FOLTZ, K.R., and JAFFE, L.A. (1999). Requirement of a Src family kinase for initiating calcium release at fertilization in starfish eggs. J Biol Chem 274: 29318-29322.

GLAHN, D., MARK, S.D., BEHR, R.K., and NUCCITELLI, R. (1999). Tyrosine kinase inhibitors block sperm-induced egg activation in Xenopus laevis. Dev Bio/205: 171-180.

HARAYAMA, H., MURASE, T., and MIYAKE, M. (2005). A cyclic adenosine 3',5'monophosphate stimulates phospholipase $\mathrm{C} \gamma 1$ calcium signaling via the activation of tyrosine kinase in boar spermatozoa. J Andro 26: 732-740.

HINTON, S.D., YANG, D., and ECKBERG, W.R. (2003). Protein tyrosine phos- phatases in Chaetopterus egg activation. Develop Growth Differ 45: 405-415.

HORNER, V.L., and WOLFNER, M.F. (2008). Transitioning from egg to embryo: triggers and mechanisms of egg activation. Dev Dyn 237: 527-544.

HOWELL, K.P., SKIPWITH, A., GALIONE, A., and ECKBERG, W.R. (2003). Phospholipase $\mathrm{C}$-dependent $\mathrm{Ca}^{2+}$ release by worm and mammal sperm factors. Biochim Biophys Res Commun 307: 47-51.

ITO, M., SHIKANO, I., ODA, S. HORIGUCHI, T., TANIMOTO, S., AWAJI, T. MITANI, H. and MIYAZAKI, S. (2008). Difference in Ca2+ oscillation-inducing activity and nuclear translocation ability of PLC $\zeta 1$, an egg-activating sperm factor candidate, between mouse, rat, human, and medaka fish. Bio Reprod78: 1081-1090.

KINSEY, W.H., and SHEN, S.S. (2000). Role of the Fyn kinase in calcium release during fertilization of the sea urchin egg. Dev Bio/225: 253-264.

KINSEY, W.H., WU, W., and MACGREGOR, E. (2003). Activation of Src-family PTK activity at fertilization: the role of the SH2 domain. Dev Bio/264: 255-262.

KLINE, D., JAFFE, L.A., and KADO, R.T. (1986). A calcium-activated sodium conductance contributes to the fertilization potential in the egg of the nemertean worm Cerebratulus lacteus. Dev Biol117: 184-193.

KUROKAWA, M., SATO, K., WU, H., FUKAMI, K., TAKENAWA, T., and FISSORE, R.A. (2004). Evidence that activation of Src family kinase is not required for fertilization-induced $\left[\mathrm{Ca}^{2+}\right]$, oscillations in mouse eggs. Reproduction 127: 441. 454.

LEE, S-J., and SHEN, S.S. (1998). The calcium transient in sea urchin eggs during fertilization requires the production of inositol 1,4,5-trisphosphate. Dev Bio/193 195-208.

LEVASSEUR, M., and MCDOUGALL, A. (2000). Sperm-induced calcium oscillations at fertilization in ascidians are controls by cyclin B1-dependent kinase activity. Development 127: 631-641.

MCGINNIS, L.K., KINSEY, W.H., and ALBERTINI, D.F. (2009). Functions of Fyn kinase in the completion of meiosis in mouse oocytes. Dev Bio/327: 280-287.

MEHLMANN, L.M., and JAFFE, L.A. (2005). SH2 domain-mediated activation of an $\mathrm{SRC}$ family kinase is not required to initiate $\mathrm{Ca} 2+$ release at fertilization in mouse eggs. Reproduction 129: 557-564.

MENG, L., LUO, J., LI, C., and KINSEY, W.H. (2006). Role of Src homology 2 domain-mediated PTK signaling in mouse zygotic development. Reproduction 132: 413-421.

NG, M.M., CHANG, F., and BURGESS, D.R. (2005). Movement of membrane domains and requirements of membrane signaling molecules for cytokinesis. Develop Cel/9: 781-790.

RUNFT, L.L., and JAFFE, L.A. (2000). Sperm extract injection into ascidian eggs signals $\mathrm{Ca}(2+)$ release by the same pathway as fertilization. Development 127 : 3227-3236.

RUNFT, L.L., JAFFE, J.A., and MEHLMANN, L.M. (2002). Egg activation at fertilization: where it all begins. Dev Bio/245: 237-254.

SAMUEL, A.D.T., MURTHY, V.N., and HENGARTNER, M.O. (2001). Calcium dynamics during fertilization in C. elegans. BMC Dev Bio/1:8.

SATO, K-I., TOKMAKOV, A.A., IWASAKI, T., and FUKAMI, Y. (2000). Tyrosine kinase-dependent activation of phospholipase $\mathrm{C} \gamma$ is required for calcium transient in Xenopus egg fertilization. Dev Bio/224: 453-469.

SATO, K-I., FUKAMI, Y., and STITH, B.J. (2006). Signal transduction pathways leading to $\mathrm{Ca}^{2+}$ release in a vertebrate model system: Lessons from Xenopus eggs. Sem Cell Dev Bio/17: 285-292.

SAUNDERS, C.M., LARMAN, M.G., PARRINGTON, J., COX, L.J., ROYSE, J., BLAYNEY, L.M., SWANN, K., and LAI, F.A. (2002). PLC2: a sperm-specific trigger of $\mathrm{Ca}^{2+}$ oscillations in eggs and embryo development. Development129: 3533-3544.

SHIBUYA, E.K., BOULTON, T.G., COBB, M.H., and RUDERMAN J.V. (1992). Activation of p42 MAP kinase and the release of oocytes from cell cycle arrest. EMBO J11, 3963-3975.

STRICKER, S.A. (1996). Repetitive calcium waves induced by fertilization in the nemertean worm Cerebratulus lacteus. Dev Bio/176, 243-263.

STRICKER, S.A. (1997). Intracellular injections of a soluble sperm factor trigger calcium oscillations and meiotic maturation in unfertilized oocytes of a marine worm. Dev Bio/186, 185-201.

STRICKER, S.A. (1999). Comparative biology of calcium signaling during fertiliza- 
tion and egg activation. Dev Bio/211, 157-176.

STRICKER, S.A. (2009a). Roles of protein kinase C isotypes during seawaterversus cAMP-induced oocyte maturation in a marine worm. MolReprod Dev 76: 693-707.

STRICKER, S.A. (2009b). Interactions between mitogen-activated protein kinase and protein kinase $\mathrm{C}$ signaling during oocyte maturation and fertilization in a marine worm. Mol Reprod Dev 76: 708-721.

STRICKER, S.A., and SMYTHE, T.L. (2003). Endoplasmic reticulum reorganizations and $\mathrm{Ca}^{2+}$ signaling in maturing and fertilized oocytes of marine protostome worms: The roles of MAPKs and MPF. Development 130, 2867-2879.

STRICKER, S.A., and SCHATTEN, G. (1989). Nuclear disassembly and nuclear lamina depolymerization during germinal vesicle breakdown in starfish. Dev Biol135, 87-98.

SWANN, K., and YU, Y.S. (2008). The dynamics of calcium oscillations that activate mammalian eggs. Int J Dev Bio/52: 585-594.

TALMOR-COHEN A., TOMASHOV-MATAR R., ELIYAHO E., SHAPIRO R., and
SHALGI R. (2004). Are Src family kinases involved in cell cycle resumption in rat eggs? Reproduction 127: 455-463.

THOMAS, S.W., and BRUGGE, J.S. (1997). Cellular functions regulated by Src family kinases. Annu Rev Cel/ Dev Bio/13: 513-609.

TOMASHOV-MATAR, R., MATTAN, L., DAFNA, T., KAPLAN-KRAICER, R., and SHALGI, R. (2007). The role of Src family kinases in egg activation. Dev Biol 312: 77-89.

TOWNLEY, I.K., SCHUYLER, E., PARKER-GUR, M. and FOLTZ, K.R. (2009). Expression of multiple Src family kinases in sea urchin eggs and their function in $\mathrm{Ca}^{2+}$ release at fertilization. Dev Bio/327: 465-477.

WHITAKER, M. (2006). Calcium at fertilization and in early development. Physiol Rev 86: 25-88.

YIN, X., and ECKBERG, W.R. (2009). Characterization of phospholipases $C \beta$ and $\gamma$ and their possible roles in Chaetopterus egg activation. Mol Reprod Dev76: 460-470.

\section{Further Related Reading, published previously in the Int. J. Dev. Biol.}

See Special Issue Pattern Formation edited by Michael K. Richardson and Cheng-Ming Chuong at:

http://www.ijdb.ehu.es/web/contents.php?vol=53\&issue=5-6

Expression patterns of Src-family tyrosine kinases during Xenopus laevis development Zoltan Ferjentsik, Radek Sindelka, Jiri Jonak

Int. J. Dev. Biol. (2009) 53: 163-168

The dynamics of calcium oscillations that activate mammalian eggs

Karl Swann and Yuansong Yu

Int. J. Dev. Biol. (2008) 52: 585-594

Fertilization triggers activation of Fyn kinase in the zebrafish egg

W Wu and W H Kinsey

Int. J. Dev. Biol. (2000) 44: 837-841

Ca2+ oscillations in the activation of the egg and development of the embryo in mammals

$\mathrm{K} \mathrm{T}$ Jones

Int. J. Dev. Biol. (1998) 42: 1-10

Localised MPF activation and mitotic phosphorylation in fertilised Xenopus eggs

$D$ Pérez Mongiovi, $P$ Chang and $E$ Houliston

Int. J. Dev. Biol. (1996) 40: S219-S220

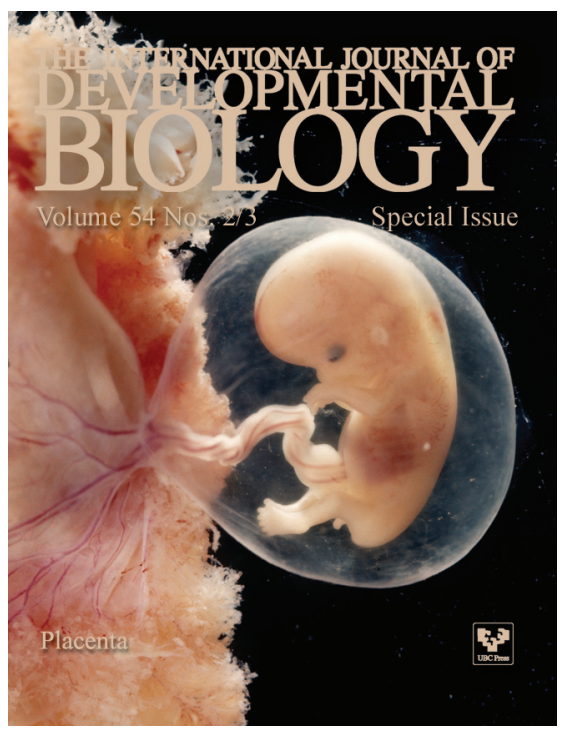

5 yr ISI Impact Factor $(2008)=3.271$

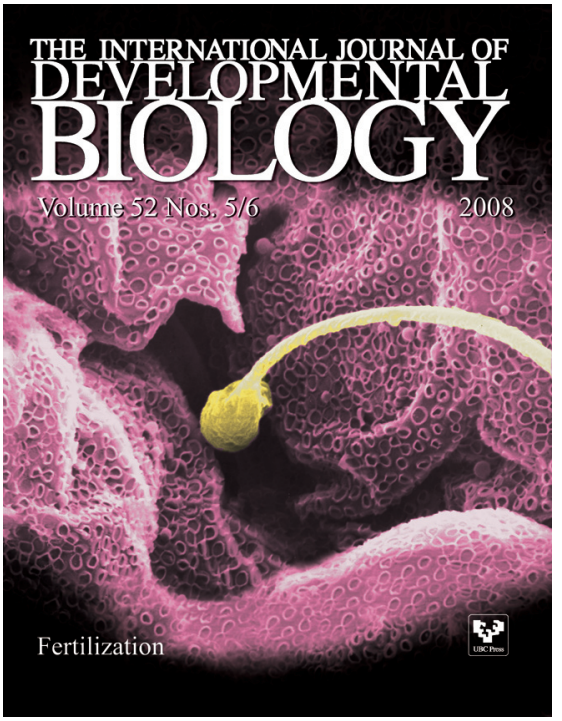

